Gut, 1976, 17, 576-580

\title{
Prognostic value of serum alpha-fetoprotein in fulminant hepatic failure including patients treated by charcoal haemoperfusion
}

\author{
IAIN M. MURRAY-LYON ${ }^{1}$, A. H. ORR, B. GAZZARD, J. KOHN, AND \\ ROGER WILLIAMS \\ From the Liver Unit, King's College Hospital and Medical School, London, and Supraregional Specific \\ Protein Reference Unit, Queen Mary's Hospital, Roehampton
}

SUMMARY Serum alpha-fetoprotein (AFP) levels have been measured sequentially by a radioimmunoassay method in 64 patients with fulminant hepatic failure. In 15 of the 64 patients $(23 \%)$ AFP levels were raised but in only two did they exceed $500 \mathrm{ng} / \mathrm{ml}$. Of the 23 survivors $11(48 \%)$ had raised AFP levels compared with four of the $41(9.8 \%)$ fatal cases $(P<0.005)$. This rise in AFP levels was found early after the development of grade IV coma and constitutes an encouraging prognostic sign at a time when the liver function tests and EEG are unhelpful. A radioimmunoassay must be used if these small but significant rises in plasma concentration are to be detected. Twelve patients survived without showing a rise in plasma AFP at any time during the illness. The four fatal cases who had raised AFP levels all had serious complications of fulminant hepatic failure. Charcoal haemoperfusion did not seem to increase the survival of AFP negative patients.

Alpha-fetoprotein (AFP) is a serum $\alpha_{1}$-globulin present in very low concentration in normal adult serum. Greatly raised levels are frequently found in patients with primary hepatocellular carcinoma, teratoma, and occasionally in other tumours (Abelev, 1971). Smaller increases in AFP concentration may occur in patients with a variety of liver disease such as viral hepatitis and cirrhosis (Kew, 1974; Ruoslahti et al., 1974; Bloomer et al., 1975a) and evidence from experimental animals suggests that this rise could be used as a marker for the regenerative response of the liver after massive liver damage (Sell et al., 1974). Indeed, a number of workers have reported that AFP levels in patients with fulminant hepatic failure may be a useful guide to prognosis particularly during the early stages of the disease when the biochemical findings and EEG are unhelpful (Opolon et al., 1973; Karvountzis and Redeker, 1974). In this paper we report our experience in 64 patients with fulminant hepatic failure using a sensitive radioimmunoassay.

\section{Methods}

The sixty-four patients investigated ranged in age 'Present address: Charing Cross Hospital, London W6. Received for publication 14 May 1976 from 15 to 64 years (males, 14, females, 50) and were in grade III or IV encephalopathy (Trey et al., 1966) at the time of study. Only two patients did not progress to grade IV coma. The aetiology of the liver disease and the distribution of the 23 survivors among the aetiological groups is shown in the Table. The four patients with drug hypersensitivity were taking isoniazid, methyl dopa, phenelzine, and pyrazinamide respectively. The blood samples-214 in all-were taken serially during the course of illness and in all but seven patients at least two samples were available. They were separated and stored at $-20^{\circ} \mathrm{C}$ until assayed.

Serum AFP was measured by a sensitive radioimmunoassay using a modification of the methods of Nishi and Hirai (1973) and Purves and Purves (1972) with polyethylene glycol as a precipitating agent (Leek et al., 1975). For the present study patients with serum concentrations greater than $50 \mathrm{ng} / \mathrm{ml}$ were considered AFP positive. Preliminary screening of sera was also performed by a cellulose acetate counter immunoelectrophoresis technique capable of producing results within 90 minutes with a sensitivity of the order of $200 \mathrm{ng} / \mathrm{ml}$ (Kohn, 1973).

Quantitative analysis of the extent of hepatocyte loss in needle samples of liver taken immediately after death was performed by a differential point 
Table Aetiology of fulminant hepatic failure in 64 cases together with number of survivors and cases with serum $\alpha$-fetoprotein levels $>50 \mathrm{ng} / \mathrm{ml}$

\begin{tabular}{|c|c|c|c|c|c|}
\hline \multirow[t]{2}{*}{ Aetiology } & \multirow[t]{2}{*}{ No. of cases } & \multicolumn{2}{|c|}{ Fatal cases } & \multicolumn{2}{|c|}{ Survivors } \\
\hline & & Total & $A F P$ positive & Total & AFP positive \\
\hline $\begin{array}{l}\text { Paracetamol overdose } \\
\text { Acute viral hepatitis }\end{array}$ & 24 & 16 & - & 8 & 3 \\
\hline Type A & 15 & 8 & 3 & 7 & 4 \\
\hline Type B & 8 & 6 & 一 & 2 & 1 \\
\hline Halothane associated & 10 & 8 & 1 & 2 & 1 \\
\hline Fatty liver of pregnancy & 2 & 1 & - & 1 & 一 \\
\hline Amanita phalloides & 1 & - & - & 1 & - \\
\hline Drug hypersensitivity & 4 & 2 & 一 & 2 & 2 \\
\hline Total & 64 & 41 & 4 & 23 & 11 \\
\hline
\end{tabular}

counting procedure using a 42-point graticule (Portmann et al., 1975). The mean value was calculated from 50 to 60 high power fields, and the result expressed as the hepatocyte volume fraction (HVF) which is the percentage of the liver volume occupied by hepatocytes. The normal range is $85 \pm 5 \%$ (Portmann et al., 1975).

\section{Results}

Only 15 of the 64 patients ( $23 \%$ ) had serum AFP levels greater than $50 \mathrm{ng} / \mathrm{ml}$ at some stage during their illness. In five patients the levels were greater than $200 \mathrm{ng} / \mathrm{ml}$ but in only two patients were the levels greater than $500 \mathrm{ng} / \mathrm{ml}$. Of these 15 AFP positive patients, all of whom who were in grade IV coma at the time of the first positive sample, 11 recovered completely. This is to be compared with 12 survivors from among the 49 AFP negative patients $\left(\chi^{2}=9.87, \mathrm{P}<0.005\right)$. Examining the results in another way, of the 23 survivors $11(48 \%)$ were AFP positive compared with four of the $41(9.8 \%)$ fatal cases.

Examination of the time when the serum AFP levels rose in relation to the clinical course (Fig. 1) shows that in each case this was on or before the fourth day of grade IV coma. In three cases in which fulminant hepatic failure followed a paracetamol overdose, AFP levels rose between the fourth and sixth day after the overdose (on the first, third, and fourth days of coma) and this time relationship was also seen in two other patients not included in this series who developed less severe liver damage without encephalopathy. In one patient levels remained raised at $120 \mathrm{ng} / \mathrm{ml}$ for only two days before returning to normal but, in most cases, values were still raised, although falling towards normal at the end of the first week. In three patients plasma levels were still raised at two weeks when the patients were fully conscious.

Each of the four AFP positive patients who died had developed a serious complication of the disease, two had haemorrhagic pancreatitis and two cases

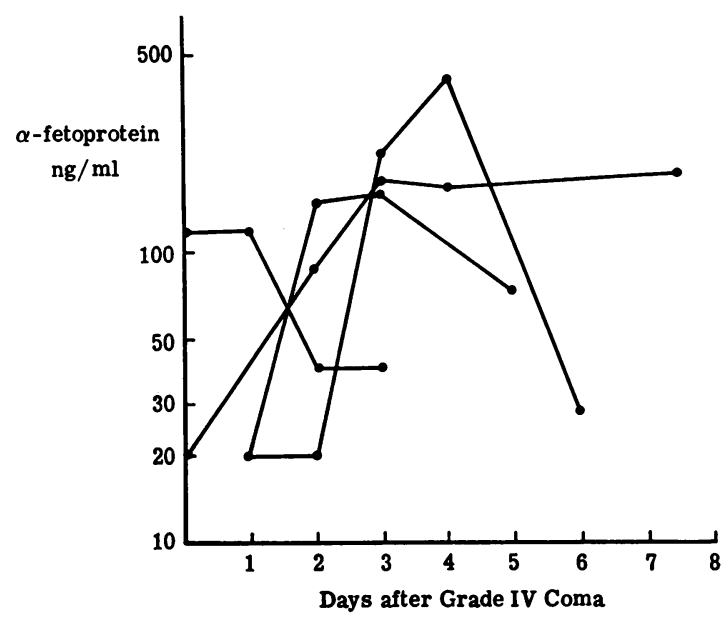

Fig. 1 Serial $\alpha$-fetoprotein levels in four representative patients at intervals after the development of grade IV coma.

had uncontrollable gastrointestinal haemorrhage. The morphometric assessment of the liver bopsies taken immediately after death in these four patients gave hepatocyte volume fraction values of $18 \cdot 8,28$, 8.7 , and $23.9 \%$. The mean hepatocyte volume fraction for the 37 AFP negative fatal cases in whom the value was available was $17 \cdot 6 \pm$ SD $11.6 \%$.

The group of 12 AFP negative patients who survived did not seem to differ in any way from the AFP positive survivors. The aetiology and the severity of their liver disease were similar in the two groups, as were the mean ages (mean 28.5 and 27.4 years respectively). Furthermore, in eight of the 12 patients plasma samples were examined up to at least the fifth day after the onset of grade IV coma, at which time raised AFP levels were always found in the AFP positive group. One such case is illustrated in Fig. 2.

Forty-three of the 64 patients were treated by charcoal column haemoperfusion, this being carried out for four hours daily until consciousness was 


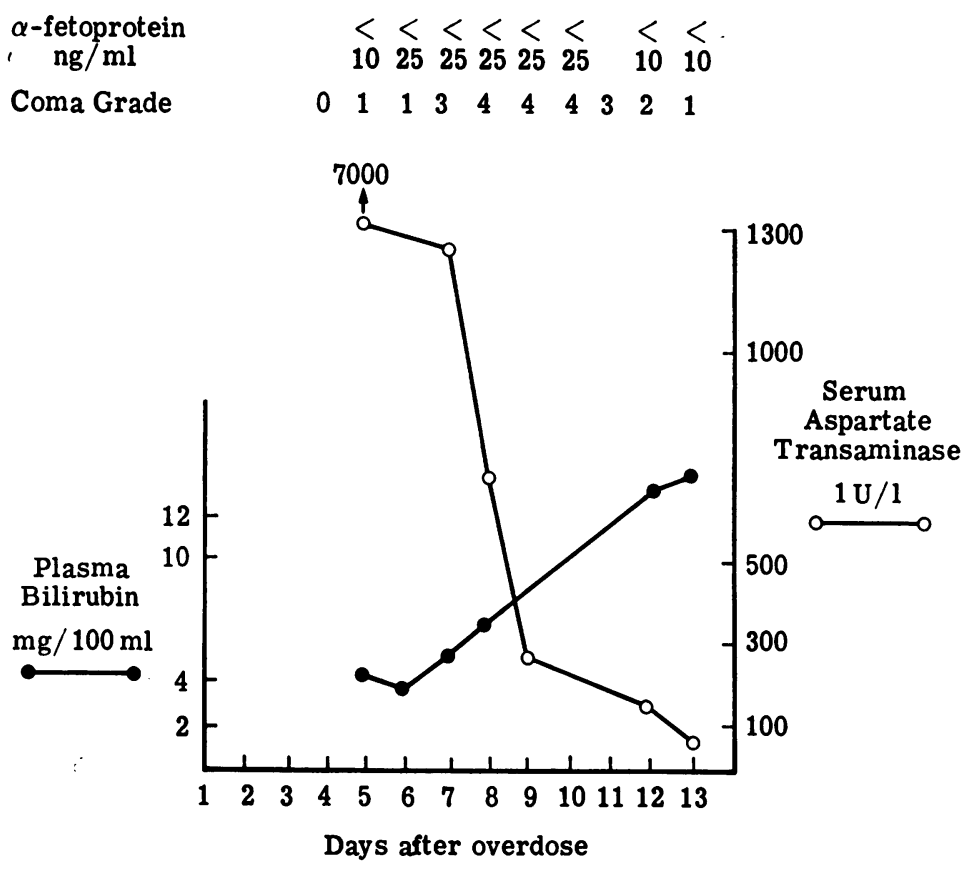

Fig. 2 Serial changes in liver function tests and grading of encephalopathy after a paracetamol overdose. Note the development of a cholestatic phase during recovery. No rise in $\alpha$-fetoprotein concentration occurred during the period of observation. regained or the patient died. Seventeen of the 23 survivors were treated and of these 11 were AFP positive and six AFP negative. Six of the 29 AFP negative patients in the charcoal treated group survived, compared with six survivors out of 20 AFP negative patients in the group not receiving charcoal perfusion.

\section{Discussion}

The development of raised plasma AFP levels found in $23 \%$ of this series of patients with FHF has been shown to be a good prognostic sign, for the survival rate of such patients $(73 \%)$ is significantly better than in those in whom AFP levels remained low ( $24 \%)$. Raised levels, when they develop, are found within the first few days of grade IV coma, at a time when the prognosis is uncertain and EEG and biochemical parameters such as prothrombin time and serum aspartate aminotransferase levels are unhelpful. In all 15 AFP positive cases the levels were raised within the first four days of grade IV coma and, although plasma samples were taken after this time from many other patients, both in the survivors and in those who died, no further patients were found to develop raised AFP levels. We do not agree, therefore, with the suggestion of Bloomer et al. $(1975 \mathrm{~b})$ that the rise in AFP levels is related to the duration of the illness rather than the final clinical outcome. The AFP positive patients in our series who died all had serious complications of fulminant hepatic failure and it is now well recognised that many such patients die from cerebral oedema, infection, or pancreatitis at a time when liver regeneration is occurring and liver function is improving (Gazzard et al., 1975a). Complications were also responsible for the deaths of eight of the 12 fatal AFP positive cases reported by Karvountzis and Redeker (1974).

Age may be an important factor determining both survival in fulminant hepatic failure and AFP response, for, at least in viral hepatitis (Bloomer et al., 1975b), there is some evidence that rises in AFP are seen more often in younger patients, but in the present series there is no difference in the mean age of AFP positive and negative survivors. The level of plasma AFP seen in 10 of the 15 AFP positive patients was $200 \mathrm{ng} / \mathrm{ml}$ or less and would not have been found by countercurrent immunoelectrophoresis (Kohn, 1973), which in its most sensitive form detects levels down to about $200 \mathrm{ng} / \mathrm{ml}$, so that it is clearly absolutely essential to use a sensitive technique like radioimmunoassay. In four patients levels lay between 40 and $50 \mathrm{ng} / \mathrm{ml}$ and they have been regarded as AFP negative because of the uncertain effects of transfusions of blood and plasma. The positivity rate using this method in our series $(23 \%)$ was lower than in the 51 patients with FHF due to viral hepatitis studied by Karvountzis and Redeker who used countercurrent immunoelectro- 
phoresis. The overall incidence of AFP positive cases in their series was $57 \%(85 \%$ survivors and $39 \%$ of fatal cases). The reasons for the difference are not clear, but they may be related to differences in the age structure of the two populations and to the aetiology of the liver disease, although when our patients with viral hepatitis are analysed separately, the results are similar to those of the overall series.

Another factor which has to be considered is that 43 of our 64 patients were treated by charcoal haemoperfusion (Gazzard et al., 1975b) on at least one occasion but studies on samples taken simultaneously from the input and output lines showed that AFP was not extracted by the column. There is no evidence that the overall low rate AFP positivity in the survivors was attributable to charcoal haemoperfusion improving the survival of AFP negative cases, for only half of these cases were so treated and the survival rate was in fact higher in the nonperfused group. The timing of the samples is also important. In the great majority of our cases several samples were taken after the onset of grade IV coma and, as AFP levels usually remain raised for at least several days (Opolon et al., 1973; Karvountzis and Redeker, 1974), it seems unlikely that we failed to detect many patients who were AFP positive. However, in the case of FHF after paracetamol overdose, the whole clinical course from the onset of liver damage to death is usually quicker than in viral hepatitis. AFP levels were raised between four and six days after the paracetamol overdose in the three AFP positive patients but in 12 of the 21 AFP negative paracetamol cases, all but one of whom died, samples were not available later than the fifth day after the overdose and so in some of these cases a subsequent rise immediately before death cannot be excluded.

It is clear from our work and also studies by Opolon et al. (1973) that AFP is not an infallible criterion for the occurrence of regeneration and full recovery from fulminant hepatic failure can occur without the levels of AFP rising. An analogy might be drawn with the two apparent populations of patients with primary hepatocellular carcinoma of whom only some $80 \%$ seem to be AFP producers (Kohn and Weaver, 1974; Bloomer et al., 1975b).

Other means of predicting the clinical outcome of the patient with fulminant hepatic failure in grade IV coma have been described recently. These include measurements of the galactose elimination capacity (Tygstrup et al., 1975), the HVF on a liver biopsy taken during the acute illness (Opolon et al., 1975), and the percentage conjugation of an intravenous trace dose of 14C-cholic acid (Horak and Waldram, 1975). None of these techniques has been shown to identify precisely those with potential for survival but the accuracy might be improved by the use of more than one method. Such an approach should be of value in planning and evaluating new methods of treatment such as charcoal haemoperfusion.

This work is part of a programme of research into liver support systems supported by the Medical Research Council and the Wates Foundation.

\section{References}

Abelev, G. I. (1971). Alpha-fetoprotein in ontogenesis and its association with malignant tumours. Advances in Cancer Research, 14, 295-358.

Bloomer, J. R., Waldmann, T. A., Mcintyre, K. R., and Klatskin, G. (1975a). Alpha-fetoprotein in nonneoplastic hepatic disorders. Journal of the American Medical Association, 233, 38-41.

Bloomer, J. R., Waldmann, T. A., Mcintyre, K. R., and Klatskin, G. (1975b). Relationship of serum alphafetoprotein to the severity and duration of illness in patients with viral hepatitis. Gastroenterology, 68, 342-350.

Gazzard, B. G., Portmann, B., Murray-Lyon, I. M., and Williams, R. (1975b). Causes of death in fulminant hepatic failure and relationship to quantitative histological assessment of parenchymal damage. Quarterly Journal of Medicine, 44, 615-626.

Gazzard, B. G., Weston, M. J., Murray-Lyon, I. M., Record, C. O., and Williams, R. (1975a). Experience at King's College Hospital with charcoal haemoperfusion: overall results in 37 patients. In Artificial Liver Support; Proceedings of an International Symposium, pp. 234-241. Edited by R. Williams and I. M. Murray-Lyon. Pitman: Tunbridge Wells.

Horak, W., and Waldram, R. (1975). Bile acid conjugation in fulminant hepatic failure. In Artificial Liver Support: Proceedings of an International Symposium, pp. 283-285. Edited by R. Williams and I. M. Murray-Lyon. Pitman: Tunbridge Wells.

Karvountzis, G. D., and Redeker, A. G. (1974). Relation of alpha-fetoprotein in acute hepatitis to severity and prognosis. Annals of Internal Medicine, 80, 156-160.

Kew, M. (1974). Alpha-fetoprotein in primary liver cancer and other diseases. Gut, 15, 814-821.

Kohn, J. (1973). Counter immunoelectrophoresis technique for the detection and identification of alpha-fetoprotein. Tumour Research (Sapporo, Japan), 8, 42-46.

Kohn, J., and Weaver, P. C. (1974). Serum-alpha ${ }_{1}$-fetoprotein in hepatocellular carcinoma. Lancet, 2, 334-337.

Leek, A. E., Ruoss, C. F., Kitau, M. J., and Chard, T. (1975) Maternal plasma alphafetoprotein levels in the second half of normal pregnancy: relationship to fetal weight, and maternal age and parity. British Journal of Obstetrics and Gynaecology, 82, 669-673.

Nishi, S., and Hirai, H. (1973). Radioimmunoassay of alphafetoprotein in hepatoma, other liver diseases, and pregnancy. Gann Monographs on Cancer Research, 14, 79-87.

Opolon, P., Hirsch-Marie, H., Gateau, P., and Caroli, J. (1973). Apparition d'alpha-1-foetoprotéine circulante au cours de l'atrophie aiguë du foie. Annales de Medicine Interne, 124, 883-888.

Opolon, P., Scotto, J., Eteve, J., Vergoz, D., Thomas, M., and Caroli, J. (1975). Liver biopsy and prognosis in acute liver failure. In Artificial Liver Support: Proceedings of an International Symposium, pp. 271-277. Edited by $\mathbf{R}$. Williams and I. M. Murray-Lyon. Pitman: Tunbridge Wells. 
Portmann, B., Talbot, I. C., Day, D. W., Davidson, A. R., Murray-Lyon, I. M., and Williams, R. (1975). Histopathological changes in the liver following a paracetamol overdose: correlation with clinical and biochemical parameters. Journal of Pathology, 117, 169-181.

Purves, L. R., and Purves, M. (1972). Serum alpha-fetoprotein. VI. The radio-immunoassay evidence for the presence of AFP in the serum of normal people and during pregnancy. South African Medical Journal, 46, 1290-1297.

Ruoslahti, E., Salaspuro, M., Pihko, H, Andersson, L., and Seppälä, M. (1974). Serum alpha-fetoprotein: diagnostic significance in liver disease. British Medical Journal, 2, 527-529.
Sell, S., Nichols, M., Becker, F. F., and Leffert, H. L. (1974). Hepatocyte proliferation and $\alpha_{1}$-fetoprotein in pregnant, neonatal and partially hepatectomized rats. Cancer $R e-$ search, 34, 865-871.

Trey, C., Burns, D. G., and Saunders, S. J. (1966). Treatment of hepatic coma by exchange blood transfusion. New England Journal of Medicine, 274, 473-481.

Tygstrup, N., Andreasen, P. B., and Ranek, L. (1975). Liver failure and quantitative liver function. In Artificial Liver Support: Proceedings of an International Symposium, pp. 286-289. Edited by R. Williams and I. M. Murray-Lyon. Pitman: Tunbridge Wells. 